\title{
MEGAEVENTOS ESPORTIVOS: BREVE ANÁLISE ECONÔMICA DA COPA DO MUNDO (FIFA)
}

\section{SPORTING MEGA EVENTS: BRIEF ECONOMIC ANALYSIS OF THE FOOTBALL WORLD CUP (FIFA)}

\author{
Elaine Carvalho de Lima* \\ Calisto Rocha de Oliveira Neto ${ }^{* *}$ \\ Érica Priscilla Carvalho de Lima ${ }^{* * *}$
}

\section{RESUMO}

A realização de megaeventos tem se tornado uma estratégia bastante utilizada, já que a promoção destes eventos pode contribuir para o desenvolvimento de uma região e estimular as relações com outros países. Neste contexto, a Copa do Mundo FIFA é um dos maiores megaeventos esportivos mundiais, pois é notória a relevância desse evento na sociedade. Assim, o presente trabalho busca realizar uma análise da Copa do Mundo FIFA destacando seus aspectos econômicos e sociais. A metodologia do trabalho é baseada em pesquisa bibliográfica e documental sobre o tema, buscando fazer uma análise do conhecimento da área de megaeventos e, sobretudo, direcionada a uma melhor contribuição dos seus impactos. Em suma, o custo de um evento não pode ser medido pela quantidade de recursos necessários para executá-lo, mas pelo valor que a sociedade perderá se esse investimento fosse alocado para um melhor projeto público.

Palavras-chave: Megaeventos Esportivos; Copa do Mundo; Legados.

\begin{abstract}
Mega-events have become a widely used strategy, since a promotion of these events can contribute to the development of a region and stimulate relations with other countries. In this context, a FIFA World Cup is one of the largest mega-sport events in the world, as the relevance of an event in society is notorious. Thus, the present work seeks to carry out an analysis of the FIFA World Cup emphasizing its economic and social aspects. A methodology of the work and research in bibliographical and documentary research on the subject, seeking an analysis of the knowledge of the area of mega-events and, above all, directed to a better contribution of its impacts. In short, the cost of an event can not be measured by the amount of resources needed to execute, but by the value that a society will lose if that investment were allocated to the best public project.
\end{abstract}

Keywords: Sports mega-events; FIFA World Cup; Legacies.

\footnotetext{
"Doutoranda em economia pela Universidade Federal de Uberlândia (UFU). Mestra e graduada em economia pela Universidade Federal do Rio Grande do Norte (UFRN). E-mail: elaine.alirn@gmail.com

${ }^{*}$ Professor da Universidade do Estado do Rio Grande do Norte (UERN). Mestre e graduado em economia pela UFRN. E-mail: calisto_neto@hotmail.com.

${ }^{* * x}$ Doutoranda em economia pela Universidade Federal de Uberlândia (UFU). Mestra em estudos urbanos e regionais pela Universidade Federal do Rio Grande do Norte (UFRN). E-mail: ericapriscillaufrn@hotmail.com
} 


\section{INTRODUÇÃO}

Nas últimas décadas, grandes interesses surgiram em sediar megaeventos esportivos. Os principais defensores desses eventos afirmam que estes podem atrair um grande número de investimentos, aumentar o fluxo turístico e provocar um impulso geral na economia com efeito duradouro sobre as regiões de acolhimento. Entretanto, sabe-se que sediar esses eventos, em geral, implica em despesas operacionais e de infraestrutura, o que pode ser extremamente oneroso, pois não é tão claro o retorno a curto e longo prazo (ANDREFF, 2006).

Há uma carência de estudos que busquem uma investigação sobre os possíveis impactos dos Megaeventos nas cidades-sede, já que muitas pesquisas verificam apenas aspectos meramente econômicos (BAADE; MATHESON, 2004). Como exemplo, os resultados de estudos de impactos econômicos feitos por consultorias contratadas pelas autoridades governamentais. No entanto, muitos pesquisadores afirmam que essas pesquisas podem ser suscetíveis a erros e manipulação, pois envolvem aspectos subjetivos sobre os verdadeiros impactos sobre determinada região (BAADE; MATHESON, 2004; IPEA, 2008).

Assim, como a determinação do impacto econômico pode ser uma tarefa desafiadora, principalmente quando não se conhece a realidade local onde o evento irá acontecer, algumas diretrizes são importantes para determinar ou identificar esses impactos. Em primeiro lugar, é necessário entender o evento e suas particularidades, para adquirir um quadro mais amplo de compreensão da magnitude de possíveis impactos. Em seguida, tentar entender a comunidade na qual o evento será realizado, bem como as atividades econômicas que são realizadas no local da sede, isso permitirá não só o entendimento das características locais da comunidade, e, principalmente, as atividades que terão relação direta com o evento. O terceiro passo, é identificar o impacto para a comunidade em questão, sendo importante se concentrar nos impactos imediatos antes de verificar os possíveis impactos a longo prazo (DOMINGUES; BETARELLI JR; MAGALHÃES, 2010).

Um dos principais exemplos de megaeventos esportivos é a Copa do Mundo de Futebol FIFA, que passou a ter uma grande relevância entre as mais diferentes nações. Neste contexto, o Brasil foi escolhido como sede da Copa do Mundo 2014 e da Copa das Confederações de 2013, após aprovação da Federação Internacional do Futebol (FIFA).

Acolher um evento desse porte significa hospedar 32 equipes e suas comitivas durante aproximadamente um mês, para isso é imprescindível uma estrutura que permita a realização das 64 partidas, além de recepcionar espectadores de todo o mundo. De modo geral, é necessário um planejamento, preparação e execução de várias etapas do evento.

Dessa forma, o presente estudo busca realizar uma breve análise do mundial da Copa FIFA destacando seus aspectos econômicos e sociais. Em termos metodológicos, a pesquisa se desenvolveu por meio de dados secundários, que foram obtidos através de dois tipos de pesquisa: documental e bibliográfica. A revisão bibliográfica sobre o tema buscou fazer uma análise do conhecimento da área de megaeventos e, sobretudo, direcionada a uma melhor contribuição dos impactos desses projetos.

Dessa maneira, o trabalho está estruturado em três seções, além dessa parte introdutória. Na segunda seção, será abordada a problemática de pesquisa, envolvendo os aspectos conceituais sobre megaeventos esportivos. A terceira seção apresenta a discussão sobre os legados e impactos dos megaeventos. A quarta seção se dedica à análise do megaevento Copa do Mundo da FIFA. Finalmente, na última seção temos as considerações finais.

\section{MEGAEVENTOS ESPORTIVOS E A COPA DO MUNDO DE 2014}

\section{Discussão de megaeventos esportivos}

Nas últimas décadas, a realização de eventos esportivos tem se tornado uma estratégia bastante utilizada. Esses eventos podem ser uma alternativa para o desenvolvimento de uma região e estimular as relações com outros países. Assim, a atração de eventos de porte internacional, com destaque para os megaeventos esportivos, tem sido observada por planejadores e governantes como uma forma de dinamizar a economia local em grandes metrópoles e de se tentar resolver graves problemas relacionados às desigualdades sociais (BAADE; MATHESON, 2004; IPEA, 2008; SWINNEN; VANDEMOORTELE, 2008). 
Dentro da classificação de eventos esportivos, os megaeventos são uma classe de destaque. Esses eventos, em geral, são de curto prazo e com efeitos de longo prazo, possuem o foco no mercado de turismo internacional e causa impactos nas cidades-sede. Podemos citar como exemplos de megaeventos: a Copa do Mundo, os Jogos Olímpicos, Commomwealth Games, Olimpíadas de Inverno, Jogos Pan-americanos, entre outros.

Não é apenas as autoridades públicas que buscam legados positivos, mas também os órgãos esportivos internacionais. Três são as possíveis justificativas: a primeira é que um legado positivo evita descontentamentos do público e dos órgãos desportivos internacionais, fornecendo provas dos benefícios de sediar o evento. Em segundo lugar, isso poderá justificar a utilização de recursos públicos escassos para a infraestrutura permanente ou temporária do evento, garantindo que todas as estruturas necessárias para a execução estarão prontas no tempo previsto para o evento. Por último, um legado positivo também estimula outras cidades ou nações para sediarem megaeventos (PREUSS, 2006).

Verifica-se que eventos esportivos como a Copa do Mundo da FIFA alteram a disposição para investir ao invés de poupar, de forma que o anúncio de um evento impulsiona o investimento. "Enquanto isso tudo impele a economia local [...] a chave para qualquer efeito em longíssimo prazo encontra-se na possibilidade de formação de um legado permanente na infraestrutura ou nas competências da indústria" (RUBIO, 2008, p. 28).

Para acolher esses eventos a cidade sede precisa oferecer alguns equipamentos relacionados ao evento, dispondo de uma rede de hotéis e uma rede de transporte que permita o deslocamento dos visitantes ao evento. Há críticas com relação aos locais que irão sediar os jogos, especialmente em países em desenvolvimento, pois o acolhimento dos megaeventos está relacionado com a criação de uma grande infraestrutura de apoio, que implica numa grande quantidade de recursos ou em dívidas de longo prazo.

Para Raeder (2010), o megaevento esportivo possui quatro fases para implementação:
Figura 1 - Fases de implementação dos megaeventos esportivos

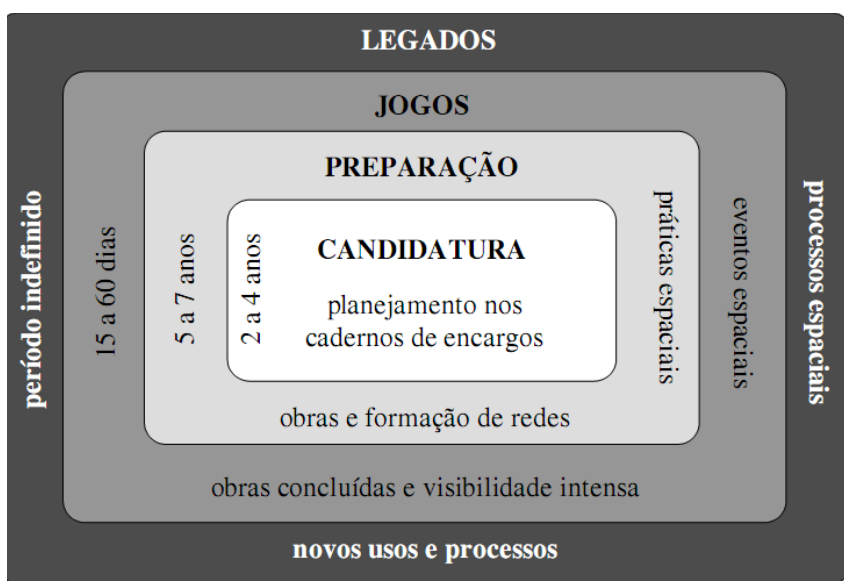

Fonte: RAEDER (2010).

$\mathrm{Na}$ fase da candidatura são estabelecidos os cadernos de encargos, que são uma espécie de contrato com a entidade responsável pelos jogos. A segunda etapa abrange o período de escolha da cidade que irá acolher o evento e o início das atividades esportivas, que em média varia de 5 a 7 anos antes da realização do evento. Nessa etapa são feitas as intervenções para a construção ou reforma das arenas esportivas e a estruturação da rede de transportes. A terceira etapa dos Jogos é a fase de realização do evento nas arenas preparadas na fase anterior, sua duração pode variar de 15 a 60 dias, esse período é marcado por uma intensa visibilidade da cidade sede. A última fase consiste nos Legados, e é bastante anunciada pelos organizadores do evento para legitimá-los, os legados que se destacam para a sede podem ser, melhorias nos transportes, como a ampliação de aeroportos, construção de novas vias e novos usos das arenas.

O relatório da "Commonwealth Games Benefits Study"1 faz algumas recomendações sobre as melhores práticas de planejamento, bem como, operações de grandes eventos e as formas de organização e construção do legado. O estudo afirma que, antes de tudo é necessário reconhecer que cada evento pode ter um único conjunto de circunstâncias que podem ajudar a ditar se vai ter sucesso ou não.

No caso dos Jogos Olímpicos nas cidades de Seul, na Coreia do Sul (1988) e Barcelona, na Espanha (1992), foram realizadas várias intervenções urbanas

\footnotetext{
${ }^{1}$ Também denominado "Jogos da Amizade", é uma competição multidesportiva e multinacional, acontece a cada quatro anos com os atletas da Commonwealth inglesa.
} 
em áreas degradadas dessas cidades. Em Seul executaram diversas remoções de favelas e a recuperação de sítios históricos. Já as transformações em Barcelona é um dos casos de maior sucesso de desenvolvimento urbano relacionados aos jogos. Na cidade foram feitas decisões locacionais compatíveis com os desafios que enfrentava. A cidade catalã utilizou a oportunidade dos Jogos para transformar a cidade, dinamizando as potencialidades turísticas e reduzindo as fragilidades sociais existentes (MASCARENHAS, 2009).

Os estudos do Instituto de Pesquisa Econômica Aplicada - IPEA (2008) mostram os resultados satisfatórios obtidos pelos Jogos Olímpicos nas cidades de Barcelona 1992 (Espanha), Sydney 2000 (Austrália) e Pequim 2008 (China), confirmam que os jogos podem resultar em legados positivos, principalmente, para as cidades que sediam esses eventos. A pesquisa elaborada pela instituição revelou que investimentos em eventos esportivos proporcionaram bons resultados nas cidades analisadas. No caso de Barcelona, a cidade saiu da fase da depressão na década de 1980 para o boom econômico após a realização do evento. Os investimentos para os Jogos Olímpicos de 1992 em Barcelona promoveram uma transformação urbana na cidade e diminuição da taxa de desemprego. O mesmo aconteceu em Sydney e em Pequim: aumento do PIB e emprego. Um dos grandes desafios contestados pelo estudo é como conseguir, depois do evento, manter o nível de atividade econômica dos anos de preparação. Assim:

Investir na cidade (e região), e não no evento, é algo que deve ser colocado como prioridade na hora de formular uma proposta de candidatura. Antes dos estádios, ginásios, piscinas, alojamentos é importante pensar na questão das facilidades de transporte e comunicação, na questão ambiental e na segurança e conforto dos turistas e atletas, por exemplo. (IPEA, 2008, p. 47)

Proni (2010) também faz algumas constatações a partir das experiências de Barcelona (1992), Sydney (2000) e Pequim (2008):

1. O megaevento pode dinamizar o turismo, gerar novos empregos e catalisar novos investimentos na infraestrutura urbana;

2. Pode beneficiar poucos segmentos econômicos e sociais, de forma que os investimentos ficam concentrados apenas nas cidades-sede;
3. É importante evitar usos abusivos de recursos públicos, como foi o caso de Atenas (2004) e dos Jogos Pan Americanos do Rio de Janeiro (2007);

4. Há uma dificuldade de estimação dos reais efeitos de um megaevento.

Os megaeventos esportivos podem beneficiar suas sedes com os investimentos realizados, por exemplo, em infraestrutura urbana. Uma infraestrutura imprópria em certa localidade, quando é revigorada devido a Copa do Mundo, pode garantir uma diminuição dos custos e fornecer um impulso da produtividade à economia (SWINNEN e VANDEMOORTELE, 2008). Barclay (2009), afirma que a vinda de novas infraestruturas, como a construção de novos estádios, por um lado pode elevar a atividade econômica, entretanto, pode elevar os custos de oportunidades para o setor público, ocasionando numa redução de outros serviços públicos.

Swinnen e Vandemoortele (2008) verificaram que em sua maioria, os governantes e empresários contratam agências de consultorias para elaborar seus estudos de impacto econômico, que no geral apontam resultados bastante otimistas para a economia. No entanto, há muitas pesquisas que criticam a validade desses estudos, apontando que muitas exageram nos resultados dos impactos econômicos em comunidades locais. Para Matheson (2006) os multiplicadores destas análises são duvidosos porque eles são baseados nos padrões normais de produção em uma área econômica, entretanto, a economia de uma cidade que for sediar tais eventos poderá se comportar de maneira diferente, invalidando esses multiplicadores.

Matheson (2002) também faz uma avaliação dos megaeventos, e no caso da Copa do Mundo, ele acredita que esse evento apenas substitui turistas usuais por "turistas-copa", esses últimos podem efetuar um gasto na cidade-sede significativamente menor, já que estes terão gastos com ingressos e deslocamentos para o evento.

Comparando as duas últimas edições da Copa do Mundo, na África do Sul (2010) e os jogos ocorridos na Alemanha (2006), é importante esclarecer que além das disparidades de renda e desenvolvimento econômico entre os dois países, é difícil transpor os impactos desse Megaevento na Alemanha para a África do Sul. Uma das diferenças entre os dois países 
foram os custos de investimento em infraestrutura. No caso da África do Sul, esses investimentos foram maiores. Enquanto, que na África do Sul havia a necessidade de construção de muitos estádios, na Alemanha isso não foi necessário, pois já tinha a maioria.

Dessa forma, o pós Copa do Mundo pode proporcionar retornos diferentes dos investimentos econômicos, como na comparação entre países de diferentes níveis de renda, no caso da Alemanha (2006) e África do Sul (2010). Quanto aos estádios, estes são bem utilizados na Alemanha com um grande comparecimento na Bundesliga ${ }^{2}$. Já na África do Sul, a demanda pelos estádios de futebol no pós Copa do Mundo se tornou algo incerto. Nota-se que o grau de utilização dos estádios para estas demandas diferentes irá afetar os benefícios para as regiões que sediaram os eventos. Assim, a baixa utilização e os altos custos de manutenção podem acarretar em um "legado" negativo desse megaevento. Depken e Wilson (2008) retratam o pós Copa do Mundo de 2002, com relação aos seus efeitos da Coréia do Sul e do Japão, ele adverte que as preocupações com a baixa utilização e altos custos de manutenção dos estádios são justificáveis.

\section{E O QUE FICA? ANÁLISE DOS LEGADOS E IMPACTOS}

Nos últimos anos, os megaeventos esportivos tem apresentado grande visibilidade, tendo em vista os possíveis impactos e legados deixados para as cidades-sede. Nesse sentido, várias discussões em torno desses temas são necessárias, já que esta "área de conhecimento ainda encontra-se em fase de construção" (SEIXAS 2010, p. 25), várias pesquisas ressaltam que o termo "legado" é complexo e multidisciplinar.

De todo modo, é importante a tentativa de se fazer uma diferenciação entre o impacto econômico e legado, mesmo em decorrência das dificuldades conceituais. Em primeiro lugar, os impactos econômicos se referem aos efeitos imediatos que são resultados da preparação e realização dos jogos, tendo em geral, uma duração de curto prazo, são provisórios e podem ser controlados. Enquanto, o legado, engloba a ideia de longo prazo e a oportunidade de valor positivo

${ }^{2}$ Liga profissional de futebol da Alemanha, informações no site: www.bundesliga.de/de/
(PRONI apud PREUSS 2006). Nesse contexto, o legado se refere às possibilidades de desenvolvimento sustentável, garantindo que o crescimento econômico da produção não comprometa as gerações futuras.

De qualquer maneira, quando se referem aos eventos esportivos, alguns legados podem não ser planejados, como as externalidades ${ }^{3}$ negativa/positiva (PREUSS, 2006). Ou seja, custos ou benefícios decorrentes de uma atividade econômica que afete uma comunidade que não está envolvida nessa atividade econômica. Dessa forma, uma melhor definição de legado pode ser: "legacy is planned and unplanned, positive and negative, intangible and tangible structures that were/will be created through a sport event and remain after the event" (PREUSS, 2006, p.3).

Preuss (2006) também afirma que na literatura podem ser encontrados vários conceitos para o termo "legado" de eventos esportivos, no entanto, são poucos que satisfazem a definição da avaliação dos "legados". Segundo o autor, entre os legados positivos se destacam: novas instalações para os eventos, melhorias na infraestrutura geral, revitalização urbana, crescimento do turismo internacional, aumento do emprego, marketing da cidade, produção de valores culturais, novas oportunidades de negócios locais, cooperação inter-regional, experiências e know-how. Enquanto, os legados negativos podem ser: elevados custos de construção, perda permanente de visitantes, aumentos das propriedades alugadas, investimentos em estruturas desnecessárias e endividamento do setor público, crescimento de empregos temporários e empresas temporárias.

Um mesmo evento sediado duas vezes na mesma cidade cria diferentes legados cada vez que é realizado, sabe-se que para a realização desses eventos é necessária uma infraestrutura esportiva para os treinamentos e competições, como também é necessário a infraestrutura da cidade, como estradas, aeroportos, telecomunicações, hotéis, estruturas para entretenimento etc. Portanto, o evento pode demandar outras necessidades em épocas diferentes. Fato semelhante acontece quando o mesmo evento é sediado em cidades diferentes, verifica-se uma dificuldade de um julgamento comparativo, pois o "sistema de alvo" de cada é diferente (PREUSS, 2006).

\footnotetext{
${ }^{3}$ As externalidades ocorrem quando os agentes numa economia interagem no mercado, gerando, sem intencionalidade, malefícios ou benefícios para indivíduos alheios ao processo.
} 
Com relação aos impactos, estes podem ser quantificados em somas de dinheiro ou outras medidas concretas, enquanto há diversos outros em que uma resposta quantitativa é quase impossível de ser alcançada. Podemos classificá-los respectivamente em impactos tangíveis (impactos econômicos na infraestrutura e modificações urbanas, por exemplo) e intangíveis (pode ser: promoção de imagem, impactos socioculturais e impactos políticos).

A literatura de economia dos esportes geralmente abrange outros impactos resultantes dos eventos esportivos, por exemplo: ampliação dos setores de serviços e hotelaria; fluxo adicional de turistas no evento; e marketing internacional do país, com atração de investimento externo. No entanto, uma característica comum desses impactos é que eles são difíceis de mensuração e projeção. Isso é devido a complexidade e a singularidade desses eventos, sendo muitas vezes inúteis prever os impactos e legados a partir das "melhores práticas" (benchmarks) de experiências do passado.

Kurscheidt (2006) menciona três razões que induz os impactos econômicos: 1) nível de investimento no estádio na fase de pré-evento; 2) os gastos de turistas estrangeiros, na fase atual e 3) resultados da "exploração" dos estádios na fase pós-evento.

Nesse sentido os investimentos são de extrema importância, pois podem gerar renda adicional pelo efeito multiplicador na economia. Contribuindo também com os gastos de turismo, já que este poderá ser impulsionado pela capacidade do estádio e pela atratividade regional direcionada para os turistas da Copa do Mundo. Outra tarefa crucial é a escolha dos locais dos jogos para o sucesso econômico do evento, isto é, uma gestão eficiente dos recursos.

Alguns aspectos sociais também devem ser considerados ao sediar esses eventos, entre eles, dinheiro público investido nos jogos cria "custos de oportunidades" significativos, ou seja, quando gastos em alguns setores essenciais, deixam de ser priorizados em benefício do evento esportivo. Dessa forma, os gestores públicos necessitam verificar os efeitos econômicos e sociais para a população. Um dos efeitos negativos que podem surgir, é que devido à criação de novas instalações para o evento, sejam necessárias desapropriação e realocação de cidadãos, especialmente em espaços que se localizavam nas áreas mais pobres, ocasionando uma valorização econômica da área e levando a perda de seu ambiente social (RUBIO, 2008).

\section{COPA DO MUNDO DA FIFA}

A Copa do Mundo de futebol teve sua origem no Olympic Football Tournament que era organizado pela Féderation Internationale de Football Association (FIFA), na França em 1924. Os bons resultados deste evento permitiram que a FIFA tivesse a competência de escolha da melhor seleção de futebol do mundo a cada quatro anos independente do Comitê Olímpico Internacional (COI). Assim, em 1929 a FIFA elegeu o Uruguai para sediar a primeira edição da Copa do Mundo, nessa época, esse país tinha a maior equipe nacional e também ganhou duas vezes consecutivas o Olympic Football Tournament. (KURSCHEIDT, 2006).

Os jogos da Copa do Mundo da FIFA evoluíram muito desde a primeira edição no Uruguai em 1930, onde treze seleções participaram, sendo nove da América (Argentina, Uruguai, Bolívia, Brasil, Chile, Paraguai, Peru, México e EUA) e quatro da Europa (Bélgica, França, Romênia e Iugoslávia), foram duas semanas de partidas.

Já em 2006, na Alemanha, as fases finais da Copa tinham 32 países classificados, dentre aproximadamente 200 que disputavam as fases eliminatórias. Os estádios estavam próximo da capacidade total instalada de público, nas 12 sedes espalhadas pelo país, disputando 64 partidas durante o mês (RUBIO, 2008). Na edição mais recente em 2010, na África do Sul, compareceram 3,18 milhões de torcedores às 64 partidas do Mundial, número um pouco menor que o recorde observado na Copa do Mundo dos Estados Unidos 1994, quando 3,59 milhões de pessoas passaram pelas catracas dos estádios americanos. A tabela abaixo mostra as sedes das 19 edições da Copa do Mundo da FIFA: 
Tabela 1 - Cidades-sede da copa do mundo- fifa

\begin{tabular}{c|c|c|c}
\hline \multicolumn{4}{|c}{ Edições da Copa do Mundo- FIFA } \\
\hline \multirow{2}{*}{ Ano } & País & Público Total & $\begin{array}{c}\text { Média de Público por } \\
\text { jogo }\end{array}$ \\
\hline 1930 & Uruguai & 434.500 & 24.000 \\
\hline 1934 & Itália & 395.000 & 23.235 \\
\hline 1938 & França & 483.000 & 26.833 \\
\hline 1950 & Brasil & 1.337 .000 & 60.772 \\
\hline 1954 & Suíça & 943.000 & 36.269 \\
\hline 1958 & Suécia & 868.000 & 24.800 \\
\hline 1962 & Chile & 776.000 & 24.250 \\
\hline 1966 & Inglaterra & 1.614 .700 & 50.459 \\
\hline 1970 & México & 1.674 .000 & 42.312 \\
\hline 1974 & Alemanha & 1.774 .000 & 42.374 \\
\hline 1978 & Argentina & 1.610 .200 & 33.967 \\
\hline 1982 & Espanha & 1.856 .200 & 43.211 \\
\hline 1986 & México & 2.403 .000 & 48.411 \\
\hline 1990 & Itália & 2.517 .300 & 68.413 \\
\hline 1994 & Estados Unidos & 3.557 .500 & 45.672 \\
\hline 1998 & França & 2.923 .000 & 42.330 \\
\hline 2002 & Coréia-Japão & 2.709 .100 & 52.500 \\
\hline 2006 & Alemanha & 3.353 .655 & 49.669 \\
\hline 2010 & África do Sul & 3178856 & 53.591 \\
\hline 2014 & Brasil & 3429873 & \\
\hline
\end{tabular}

Fonte: Elaboração própria da autora, a partir de informações do site FIFA

Após a Segunda Guerra Mundial, a competição teve um grande crescimento com a contribuição das novas tecnologias que possibilitaram a cobertura no evento em âmbito mundial, passando a ser televisionada a partir de 1954. Atualmente, a Copa do Mundo não é apenas a principal fonte de recursos financeiros da FIFA, sendo também um evento bastante disputado por diversos países que possuem vários interesses em sediar este megaevento, tais como, impactos socioeconômicos positivos no esporte, desenvolvimento nacional e regional.

Ao longo dos últimos anos, especialmente com o fenômeno da "globalização", houve uma ampla integração dos mercados, transportes e comunicação. Assim, o esporte ingressou como uma das formas de indústria de entretenimento e está diretamente associada ao mundo dos negócios. As inovações tecnológicas permitiram uma maior integração entre os diversos países, e como o esporte possui uma linguagem universal, isso reforça a ideia de que esses eventos sejam um poderoso recurso de articulação política, social e econômica (PEREIRA, 2009). Por exemplo, as inovações tecnológicas das transmissões por satélite, da Copa do México (1970) e das Olimpíadas de Munique (1972), e posteriormente com a mídia e a internet, se tornaram um poderoso instrumento no processo de globalização dos times, patrocinadores, marcas esportivas e a difusão de produtos com as principais marcas (com o selo FIFA). Na edição mais recente da Copa, na África do Sul em 2010, foi utilizado pela primeira vez nos jogos o Índice Castrol, que é uma inovação tecnológica, que utiliza métodos estatísticos para examinar e classificar os resultados individuais dos jogadores.

Em meados dos anos 1970 houve um grande impulso ao marketing esportivo, grandes empresas multinacionais passaram a criar estratégias globais de marketing e a promoção de eventos esportivos permitiu uma expansão enorme de mercados consumidores. Destacam-se a Coca-Cola e a Philips Morris que utilizavam esses eventos como estratégia de divulgação por diversos países, patrocinando a Copa do Mundo e 
a Fórmula 1, respectivamente. Com o passar dos anos, a utilização do esporte como veículo de propaganda e merchandising aumentou bastante. "Atualmente, o esporte é considerado uma das 'atividades econômicas' que mais crescem nos mercados globalizados, o que tem estimulado a entrada de grandes corporações empresariais e tem requerido métodos modernos de administração" (PRONI, 1998).

A FIFA é constituída por 208 federações afiliadas, estas recebem ajuda financeira e apoio logístico por meio de programas da federação. Para sediar uma Copa do Mundo o país selecionado passa por um processo rigoroso de exigências estabelecidas pela FIFA, entre elas: construção de novos estádios ou reformar os antigos, modernização e melhorias na acessibilidade ao evento.

A Copa do Mundo se tornou uma marca global e um produto bastante valorizado, sem levar em conta o crescimento do patriotismo de um país que reúne quase toda sua população representada por uma equipe.

De acordo com Kurscheidt (2006), a Copa do Mundo é "instrumento econômico" utilizado em diversos níveis: 1) é a base de financiamento econômico da FIFA; 2) assume um papel semelhante para as corporações patrocinadoras da FIFA, com destaque para a indústria de artigos esportivos; 3) é uma oportunidade para os jogadores profissionais ascenderem sua carreira; 4) pode ser (ou não) um caminho para o desenvolvimento econômico para os países e cidades de acolhimento dos jogos.

As competições da Copa do Mundo podem ser economicamente caracterizadas da seguinte maneira; são organizadas em um campeonato em que a marca global, FIFA, é a detentora dos direitos de propriedade exclusiva. Esta organização econômica é uma fornecedora monopolista do direito de sediar a Copa do Mundo em um determinado ano e locais escolhidos de um determinado país. Assim, a FIFA funciona como um sistema de franquia, no entanto, diferentemente da relação de longo prazo entre sócios de uma franquia, o direito de sediar o evento é limitado por um único campeonato em um determinado período de tempo, sendo que o país selecionado é alocado para o evento em uma espécie de "leilão" com vários licitantes concorrentes.

Cada vez mais, a FIFA busca atingir novos mercados com a Copa do Mundo. Algumas constatações evidenciam essa expansão: a Copa de 1994 nos Estados Unidos desfez uma antiga tradição de que o evento fosse realizado alternadamente nas regiões da Europa e América do Sul. Já em 1996, o Comitê Executivo da FIFA selecionou um país asiático para sediar a Copa de 2002, sendo o primeiro evento organizado pela Coréia do Sul e Japão. Nos dois casos, as escolhas não foram, certamente, por motivos de méritos do futebol, mas por razões estritamente econômicas (BAADE e MATHESON, 2004).

A tabela 2 mostra a expansão do número de equipes participantes das edições da Copa do Mundo. Verifica-se que a partir de 1982 houve uma elevação de 16 para 24 equipes, já em 1998 há um aumento de 24 para 32 equipes, o que permanece nas edições mais atuais. Isso evidencia não só o crescimento no esporte, mas também objetivos estritamente econômicos, como a maximização das vendas de tickets para entrada nos estádios, abertura e ampliação de novos negócios.

Tabela 2 - Estatísticas da copa do mundo, 1930-2010

\begin{tabular}{c|c|c|c|c}
\hline Edições & Ano & País sede & $\mathrm{N}^{\mathrm{o}}$ de equipes & $\mathrm{N}^{\mathrm{o}}$ de cidades/estádio \\
\hline $1^{\mathrm{a}}$ & 1930 & Uruguai & 13 & $1 / 3$ \\
\hline $2^{\mathrm{a}}$ & 1934 & Itália & 16 & $8 / 8$ \\
\hline $3^{\mathrm{a}}$ & 1938 & França & 15 & $9 / 10$ \\
\hline $4^{\mathrm{a}}$ & 1950 & Brasil & 13 & $6 / 7$ \\
\hline $5^{\mathrm{a}}$ & 1954 & Suíça & 16 & $6 / 6$ \\
\hline $6^{\mathrm{a}}$ & 1958 & Suécia & 16 & $12 / 12$ \\
\hline $7^{\mathrm{a}}$ & 1962 & Chile & 16 & $4 / 4$ \\
\hline $8^{\mathrm{a}}$ & 1966 & Inglaterra & 16 & $7 / 8$ \\
\hline $9^{\mathrm{a}}$ & 1970 & México & 16 & $5 / 5$ \\
\hline $10^{\mathrm{a}}$ & 1974 & Alemanha & 16 & $9 / 9$ \\
\hline
\end{tabular}




\begin{tabular}{c|c|c|c|c}
\multicolumn{1}{l}{ conclusão } \\
\hline Edições & Ano & País sede & $\mathrm{N}^{\mathrm{o}}$ de equipes & $\mathrm{N}^{\mathrm{o}}$ de cidades/estádio \\
\hline $11^{\mathrm{a}}$ & 1978 & Argentina & 16 & $5 / 6$ \\
\hline $12^{\mathrm{a}}$ & 1982 & Espanha & 24 & $14 / 17$ \\
\hline $13^{\mathrm{a}}$ & 1986 & México & 24 & $9 / 12$ \\
\hline $14^{\mathrm{a}}$ & 1990 & Itália & 24 & $12 / 12$ \\
\hline $15^{\mathrm{a}}$ & 1994 & Estados Unidos & 24 & $9 / 9$ \\
\hline $16^{\mathrm{a}}$ & 1998 & França & 32 & $9 / 10$ \\
\hline $17^{\mathrm{a}}$ & 2002 & Coréia-Japão & 32 & $20 / 20$ \\
\hline $18^{\mathrm{a}}$ & 2006 & Alemanha & 32 & $12 / 12$ \\
\hline $19^{\mathrm{a}}$ & 2010 & África do Sul & 32 & $9 / 10$ \\
\hline
\end{tabular}

Fonte: KURSCHEIDT (2006).

Em 3 de agosto de 2000, o Comitê executivo da FIFA aderiu ao sistema de rotatividade, permitindo o acesso a todos os países interessados por um novo processo de licitação para sediar a Copa do Mundo, a decisão aconteceu no $52^{\circ}$ Congresso Ordinário da FIFA, em Zurique. Em 2001, a FIFA decidiu que o princípio de rotação começaria na África, e em 2003, ficou decidido que a América do Sul irá sediar os Jogos de 2014 (FIFA, 2007).

Com relação a Copa do Mundo da África do Sul, informações do site oficial da Copa da África 2010, destacam que os recursos destinados para a Copa de 2010 foram baseados em um programa de financiamento do tesouro nacional que priorizou o investimento em infraestrutura, comunicação, segurança e logística, sendo que as principais instalações começaram a ser construídas em 2007.

Nesse contexto, do total de dez estádios disponíveis para sediar a Copa, cinco foram construídos, são estes: Greenpoint Stadium, Nelson Mandela Bay, Moses Mabhida Stadium, Mataffin Stadium e Peter Mokaba Stadium. Enquanto, os demais passaram por reformas: Royal Bafokeng Stadium, Vodacom Park, Ellis Park Stadium, The Soccer City Stadium e Loftus Versveld Stadium. Os investimentos nos 10 estádios geraram aproximadamente 66 mil postos de trabalho, principalmente, para famílias de baixa renda.

The Soccer City é o maior estádio do continente africano e foi responsável por receber os jogos de abertura e os jogos finais da Copa de 2010, localizado em Johannesburg, centro econômico da África, que possui o principal aeroporto africano: Aeroporto Internacional de Johannesburg.
A Cidade do Cabo (Cape Town) é a segunda maior cidade da África do Sul, recebeu uma das semifinais dos jogos da Copa no estádio Greenpoint, este foi construído com a capacidade para $70 \mathrm{mil}$ pessoas, após os jogos houve uma redução para 55 mil lugares, recebendo também eventos culturais e shows. A partir das experiências da Copa da Alemanha em 2006, as cidades mencionadas, Johannesburg e a Cidade do Cabo, aderiram ao programa da FIFA, Green Goal, que objetiva a redução das emissões de CO2 nos eventos.

Aproximadamente 3,1 milhões de espectadores assistiram aos 64 jogos da Copa do Mundo da FIFA 2010 nos 10 estádios. As informações divulgadas pelo site oficial mostram que aproximadamente 1,4 milhões de estrangeiros visitaram a África do Sul durante os jogos de 2010, devido a grande quantidade de turistas a África do Sul passou a ofertar vistos específicos para o evento.

Um dos principais desafios para as sedes da Copa 2010 foi a questão da mobilidade urbana, uma das soluções encontradas foi a utilização do Metrorail, que eram trens que transportavam gratuitamente os passageiros que tivessem os bilhetes para a Copa 2010, o Metrorail era direcionado para os estádios e tinha finalidade de evitar os congestionamentos nas estradas. Também foram disponibilizados 700 ônibus para utilização no evento.

Entretanto, apesar de todo entusiasmo, o evento se tornou preocupante para a população sul-africana, especialmente quanto aos legados prometidos, os altos custos decorrentes da instalação do evento e a má gestão dos recursos (COTTLE, 2011). Para além dessa discussão, ao que tudo indica, os legados gerados 
foram mínimos, em que o grande ganhador foi a FIFA (MARCHI JÚNIOR; BOLSMANN; ALMEIDA; SOUZA, 2014).

O Brasil sediou a Copa do Mundo em 2014, pela segunda vez o país acolheu esse tipo de evento, anteriormente em 1950 em outro contexto social e econômico. As promessas advindas para hospedar tal evento, não poderiam ser diferentes dos demais locais, se direcionavam a oportunidade de catalisar investimentos, melhorias na infraestrutura do país e nas condições de vida da população brasileira.

Em 2007 ocorreu a oficialização que garantia ao Brasil a realização da Copa 2014, após a aprovação da FIFA em Zurique, na Suíça. Através do documento oficial, a FIFA destaca para a comunidade do futebol e população em geral: "[...] will gain considerably from the hosting of the 2014 FIFA World Cup ${ }^{\mathrm{TM}}$ in Brazil in terms of the economy, transport, communication, public services and facilities, safety and the enhancement of sporting facilities" (FIFA, 2007).

Um dos documentos disponibilizados para o público é o "Football Stadiums: Technical Recommendations and Requirements" $(2007)^{4}$, este manual contempla as exigências e orientações para a construção e reforma dos estádios. Para atender a uma grande demanda, essas são as principais exigências requeridas:

1. Decisões de pré-construção: aconselha elaborar um estudo de viabilidade do estádio, levando em consideração que o período de vida útil dos estádios modernos é de 30 anos. É importante compatibilizar o tamanho e o nível de conforto do estádio com sua futura demanda de utilização, respeitando a restrição orçamentária para a construção. Com relação à localização do estádio, a instituição orienta para a existência de estacionamentos para veículos ao redor do estádio, incentivando também a utilização de transporte de massa. É necessário que a localização do estádio permita um bom acesso e fácil circulação para a rede hoteleira, centros comerciais e aeroportos.

2. Orientação do campo: deve ser adaptado de acordo com as especificidades regionais. Todos os participantes do evento devem ser protegidos do ofuscamento dos raios solares. No caso da existência de cobertura, o material utilizado deve

\footnotetext{
${ }^{4}$ FIFA (Ed). 2007. Football Stadiums: Technical Recommendations and Requeriments ( $4^{\text {th }}$ editon). FIFA, Zurique. Disponível em: $<$ http:// www.fifa. com>.
}

possibilitar uma boa ventilação e recebimento de luz solar para o gramado.

3. Segurança: é um dos itens prioritários da FIFA. A segurança do torcedor deve ser garantida por uma seria de recomendações: câmeras de vigilância internas e externas, sala de primeiros socorros, sinalização de portas e corredores, entre outras medidas.

4. Estacionamento: torcida, público VIP, delegações, veículos de emergência e segurança, veículos de transmissão via satélite e a existência de um heliporto nas proximidades do estádio.

5. Área do Jogo: são feitas exigências para o gramado, recomenda a existência de barreiras separando as arquibancadas do campo de jogo, com a presença de seguranças e policiais para evitar invasão de torcedores.

6. Vestiários e acessos: área de entrada exclusiva para jogadores e árbitros que permita a circulação de veículos. Faz algumas recomendações sobre os escritórios dos técnicos, vestiário dos árbitros, túnel de acesso.

7. Conforto do público: cobertura para áreas de alta incidência solar e de climas frio; assentos VIPs com localização central e separada das cadeiras do público geral; garantia de uma perfeita visibilidade do campo; os estádios modernos devem ter no mínimo cinco pontos de venda para cada mil torcedores; atendimento das normas de acessibilidade para portadores de deficiência.

8. Mídia: cabine de imprensa, cabines de rádio e TV, estúdios de televisão, centro de mídia, sala de coletiva de imprensa, zona mista etc.

9. Energia e iluminação: existência de um sistema alternativo de geração de energia, em ocasião de falta de energia elétrica.

10. Green Goal (sustentabilidade): A preocupação com o meio ambiente vem sendo enfatizada, pois um evento desse porte pode causar sérios impactos ambientais. A FIFA incentiva a adoção de projetos sustentáveis, entre eles o Green Goal, é um programa da instituição que objetiva a redução das emissões de $\mathrm{CO} 2$ em seus eventos. Aborda quatro pontos:

a) Água: armazenagem de água potável para irrigação e utilização nas instalações sanitárias;

b) Resíduos: coleta seletiva de lixo e a comercialização de comidas e produtos sem embalagem, para restringir o lixo gerado durante o evento; 
c) Energia: utilização de estratégias alternativas para economia de energia;

d)Transporte: utilização de sistema de transporte público, como ônibus e trens.

No documento de candidatura, o Governo Federal assumiu alguns compromissos para assegurar a execução da Copa no país. Entre as principais Garantias Governamentais estabelecidas pela FIFA, podem ser citados: permissão de entrada e saída do país para membros da FIFA, parceiros comerciais e espectadores com ingressos; permissões de trabalho para estrangeiros em atividades relacionadas à Copa do Mundo; isenção geral de impostos a FIFA e seus parceiros comerciais e operacionais; autorização para bancos e câmbios na entrada e saída irrestrita de moedas estrangeiras, bem como na troca e conversão irrestrita destas moedas para dólares dos EUA, Euros ou Francos Suíços, para a FIFA e parceiros comerciais; proteção e exploração de direitos comerciais; todos os hinos e bandeiras de países participantes das competições deverão ser reproduzidos, entre outras garantias.

A despeito da boa aceitação do evento no país quanto a possibilidade de geração de benefícios à população. Observa-se que os resultados nem sempre são tão otimistas como são "vendidos". Tal fato torna-se preocupante em países em desenvolvimento e com histórico de grandes disparidades sociais e econômicas, como é o caso do Brasil.

Andreff (2006) declara que para além das declarações dos governos, o esporte não é uma área prioritária no orçamento dos países em desenvolvimento. Isso só levanta o questionamento até que ponto vale a pena sediar esses eventos, especialmente em alocar recursos que poderiam ir para as principais demandas sociais desses países.

Além disso, alguns aspectos negativos foram verificados no Brasil, como a remoção forçada de famílias de suas residências em prol dos interesses do capital na especulação imobiliária. Silva (2016) destaca que esse risco foi mais recorrente nos preparativos da Copa de 2014 do que entre as edições anteriores de 1994 a 2014. Os protestos contra FIFA e o governo evidenciados nas mídias nacionais e internacionais mostraram o lado obscuro que envolve não só a FIFA, como a Confederação Brasileira de Futebol (CBF), os atores políticos e as construtoras das arenas.
Em suma, um planejamento adequado torna-se primordial para a realização do evento e possível geração de benefícios locais. Além disso, há uma necessidade de proximidade dos comitês organizadores e dos estados com as necessidades da população, o que nem sempre ocorre. Por isso, sediar um evento dessa proporção, como a Copa do Mundo, traz uma série de dilemas quanto aos legados deixados para os locais que os hospedam. Dessa forma, o questionamento que é levantado é até que ponto vale a pena sediar tais eventos?

\section{CONCLUSÃO}

Como visto nas seções anteriores, os defensores dos megaeventos esportivos afirmam que esses eventos atraem um grande número de visitantes, provocando um impulso geral a economia com efeito duradouro sobre as regiões de acolhimento. Entretanto, sabe-se que sediar esses eventos, em geral, implica em despesas operacionais e de infraestrutura, o que pode ser extremamente oneroso, pois não é tão claro o retorno a curto e longo prazo, nas regiões que sediam esses megaeventos.

O questionamento que permanece é que, se a análise realizada por agentes com interesses no resultado, pode ser considerada um exame objetivo dos verdadeiros impactos econômicos dos eventos. $\mathrm{Na}$ literatura encontramos análises que chamam atenção para algumas observações, como a de que os estudos de impacto econômico frequentemente extrapolam o verdadeiro impacto do evento, muitas vezes há falhas na contextualização do impacto com a referência local e a posição econômica da região. Além disso, os estudos mais amplos podem incluir importantes efeitos intangíveis, tentando associar esses ao evento e aos indicadores sociais, o que na prática são difíceis de mensuração real (como, fitness e saúde, participação do esporte e criminalidade juvenil).

Por isso, é essencial ser realista sobre os possíveis benefícios da Copa do Mundo, para que estes não se percam em projetos superestimados e que não atendam as necessidades locais da comunidade. Desse modo, se faz necessário um planejamento adequado para o sucesso do evento. De forma que é essencial a proximidade dos Comitês Organizadores com a população, tendo em vista perceber suas necessidades, 
dirimir possíveis dúvidas, para que haja uma parceria entre o ente público e a população.

No caso do Brasil, a conta em termos sociais torna-se maior, especialmente por se tratar de um país bastante heterogêneo e desigual. Ademais, os legados e impactos não se mostraram dinamizadores na economia do país. Ao contrário, muitas das arenas construídas não se mantiveram viáveis economicamente e, ao que tudo indica, se tornaram elefantes brancos, pois muitas não conseguem pagar suas contas de manutenção mensal.

\section{REFERÊNCIAS}

ANDREFF, W. Sport and financing. In ANDREFF, W.; SZYMANSKI, S. (Eds.), Handbook on the Economics of Sport, Cheltenham, UK, and Northampton/MA: Edward Elgar, 2006.

BAADE, R.A; MATHESON, V.A. The quest for the cup: Assessing the economic impact of the World Cup, Regional Studies, 38, 343-354, 2004.

COTTLE, E. South Africa's World Cup: a legacy for whom? University of KawaZulu, Natal Press, 2011.

DEPKEN, C. A; WILSON, D. P. The long-run impacts of the World Cup. Southern Economic Association meetings. Washington-DC. 2008.

DOMINGUES, E. P.; BETARELLI JR., A. A.; MAGAlHÃES, A. S. Copa do mundo 2014: Impactos econômicos no Brasil, em Minas Gerais e Belo Horizonte. CEDEPLAR, Belo Horizonte, 2010. Disponível em: $<$ http://www.cedeplar.ufmg.br/seminarios/seminario_ diamantina/2010/D10A119.pdf>.

FIFA. Football Stadiums: Technical Recommendations and Requeriments (4 ${ }^{\text {th }}$ editon), 2007. FIFA, Zurique. Disponível em: <http:// www.fifa.com>.

FIGUEIREDO, F. F.; LIMA, E. C.; ARAUJO, M. A. OS IMPACTOS E LEGADOS NEFASTOS DOS MEGAEVENTOS ESPORTIVOS NO BRASIL: COPA DO MUNDO DE 2014 E JOGOS OLÍMPICOS 2016. In: XIV Ecuentro de Geógrafos de America Latina (XIV EGAL), 2013, Lima. Anais do XIV EGAL, 2013. v. 1. p. 1-14.

KURSCHEIDT, M. The World Cup. In ANDREFF, W.; SZYMANSKI, S. (Eds.), Handbook on the Economics of Sport, Cheltenham, UK, and Northampton/MA: Edward Elgar 2006, pp. 197-213.

IPEA - INSTITUTO DE PESQUISA ECONÔMICA APLICADA. Leitura Econômica dos Jogos Olímpicos: financiamento, organização e resultados. IPEA, 2008.
MARCHI JÚNIOR, W.; BOLSMANN, C.; ALMEIDA, B. S.; SOUZA, J. A copa do mundo FIFA na África do Sul/2010como foi a experiência e o que podemos aprender com ela? Movimento, Porto Alegre, v. 20, n. 2, p. 711- 733, 2014.

MASCARENHAS, G.; BORGES, F. S. da. Entre o empreendedorismo urbano e a gestão democrática da cidade: dilemas e impactos do Pan-2007 na Marina da Glória. Esporte e Sociedade, n.10, p. 1-26, 2009. Disponível em $<$ http://www.uff.br/esportesociedade/pdf/es1004.pdf $>$.

MATHESON, V. A. Upon Further Review: an examination of sporting event economic impact studies. The Sport Journal, vol. 5, nº 1, 2002.

MATHESON, V. A. Mega-events: The effect of the world's biggest sporting events on local, regional, and national economies, Holy Cross Working Paper Series, n' ${ }^{\circ}$ 06-10, 2006.

PEREIRA, T. G. Eventos esportivos e sua influência no contexto social. 2009. 31 f. Monografia (Curso de Educação Física )-Universidade Federal de Minas Gerais. Minas Gerais, 2009.

PREUSS, H. Winners and losers of the olympic games. In B. Houlihan (ed), Sport \& Society, 2. Pag. 415-438. London, Thousand Oaks, CA \& New Dehli: Sage, 2006.

PRONI, M. W. Observações sobre os impactos econômicos esperados dos jogos olímpicos de 2016. IN Motrivivência Ano XXI, No 32/33, p. 49-70 Jun-Dez./2010.

RAEDER, S. Planejamento urbano em sedes de megaeventos esportivos. PLURIS 2010, $4^{\mathbf{0}}$ Congresso para o Planejamento Urbano, Regional, Integrado e Sustentável. Universidade do Algarve, em Faro, Portugal, 2010.

RUBIO, K. Jogos olímpicos, políticas e cultura: qual o legado de Berlim - 1936? In Rubio, Katia (org). Megaeventos esportivos, legado e responsabilidade social. São Paulo, Casa do Psicólogo, 2008.

SEIXAS, T. Copa do Mundo de Futebol FIFA Brasil 2014: Uma Análise da Candidatura de Pernambuco como Subsede. Porto: T. Seixas. Dissertação de Mestrado Apresentada à Faculdade de Desporto da Universidade do Porto, 2010.

SILVA, D. S. A Copa do Mundo da FIFA 2014 veio ao Brasil: a gestão do estado de São Paulo como sede / Dirceu Santos Silva. - Campinas, SP: [s.n.], 2016. Faculdade de Educação Física.

SWINNEN, J.; VANDEMOORTELE, T. Sports and development: in economic perspective on the impact of the 2010 World Cup in South Africa. ICSSPE Bulletin, v. 53, p. $1-6,2008$. 